\section{政 Heighten Science \\ P U B L I C I T I O N S Corporation ISSN 2575-0186}

*Address for Correspondence: Mohammad Hasanzadeh, Drug Applied Research Center, Tabriz University of Medical Sciences, Tabriz 51664, Iran, Tel: +98(41)-33363311; Fax: +98(41)33363231; Email: mhmmd hasanzadeh@yahoo.com; hasanzadehm@ tbzmed.ac.ir

Submitted: 16 December 2016 Approved: 06 January 2017

Published: 09 January 2017

Copyright: @ 2017 Hasanzadeh et al. This is an open access article distributed under the Creative Commons Attribution License, which permits unrestricted use, distribution, and reproduction in any medium, provided the original work is properly cited.

Keywords: Polymeric composites Electrodeposition; Interfaces; Oxidation; Polydopamine; L-Tryptophan

Abbreviations: PDA: Poly-dopamine; PDA$\beta$-CD-GCE: poly-dopamine-beta-cyclodextrin modified glassy carbon electrode; L-Trp: L-Tryptophan; I: peak current; Ep: Peak potential; A: electrode surface area; D: the diffusion coefficient; $C^{*}$ : the bulk concentration of selected analyte; $R$ : universal gas constant (8.314 $\left.\mathrm{J} \mathrm{K}^{-1} \mathrm{~mol}^{-1}\right)$; F: Faraday constant $(96,487$ $\left.\mathrm{C} \mathrm{mol}^{-1}\right)$; T: Kelvin temperature (298 K); $\beta_{\mathrm{n}}$ : electron transfer coefficient; PBS: phosphate buffer solution; CNFs: carbon nanofibers; GCE: Glasssy carbon electrode; MWCNTs: Multiwall carbon nanotubes; Tyr: Tyrosine; CPE: Carbon past electrode; ERGO: electrochemically reduced graphene oxide; Ag@C: silver/carbon core-shell; GNP: Gold nanoparticles; CV: Cyclic voltammetry; DPV: Differential pulse voltammetry

\title{
Poly-dopamine-Beta-Cyclodextrin Modified Glassy Carbon Electrode as a Sensor for the Voltammetric Detection of L-Tryptophan at Physiological pH
}

\author{
Mohammad Hasanzadeh ${ }^{1,2 *}$, Nasrin Shadjou ${ }^{3,4}$, Sattar \\ Sadeghi ${ }^{5}$, Ahad Mokhtarzadeh ${ }^{5,6}$ and Ayub karimzadeh ${ }^{5}$ \\ 'Drug Applied Research Center, Tabriz University of Medical Sciences, Tabriz 51664, Iran \\ 2Pharmaceutical Analysis Research Center and Faculty of Pharmacy, Tabriz University of \\ Medical Sciences, Tabriz 51664, Iran \\ ${ }^{3}$ Department of Nanochemistry, Nano Technology Research Center, Urmia University, Urmia \\ 57154 , Iran \\ ${ }^{4}$ Department of Nano Technology, Faculty of Science, Urmia University, Urmia 57154, Iran \\ ${ }^{5}$ Department of Biochemistry, Higher Education Institute of Rab-Rashid, Tabriz, Iran \\ ${ }^{6}$ School of Medicine, Gonabad University of Medical Sciences, Gonabad, Iran
}

\section{ABSTRACT}

The main purpose of this report was to develop application of poly-dopamine-beta-cyclodextrin modified glassy carbon electrode (PDA- $\beta$-CD-GCE) towards electrooxidation and determination of L-Tryptophan (L-Trp) and also the evaluation its kinetic parameters. In continuation of our efforts to use PDA- $\beta$-CD-GCE for amino acids detection, our objective in the present work was to expand application of this sensor for the determination of L-Trp which is very sensitive.

\section{INTRODUCTION}

Tryptophan (Trp) is one of the most important essential amino acids having biochemical, nutritional and clinical significance in humans and herbivores [1]. Trp is commonly synthesized in plants and microorganisms from shikimic acid [2]. Trp is abundantly present in oats, milk, chocolates, bananas, yogurt, dried dates, etc. as component of dietary protein while it is scarcely present in vegetables. Hence, it has been supplied through food products to avoid its deficiency [3-5]. Trp is one of the basic constituents of protein and a requisite in human nutrition to establish and maintain a positive nitrogen balance [6]. Trp acts as precursor for serotonin, melatonin and niacin [7]. Improper metabolism of Trp accumulates toxic products in brain which causes hallucinations, delusions and schizophrenia [8]. An overdose of Trp creates drowsiness, nausea, dizziness and loss of appetite [9]. The level of Trp in blood closely relates to serotonin and melatonin level in the brain while the same in plasma relates to hepatic disease [10]. Hence, Trp is very essential for people with anxiety, sleep deprivation and the need for mood enhancement. It is also used as a sleep aid, nutraceutical and antidepressant [11]. Therefore, developing a simple, fast, inexpensive and accurate

How to cite this article: Hasanzadeh M, Shadjou N, Sadeghi S, Mokhtarzadeh A, karimzadeh A. Poly-dopamineBeta-Cyclodextrin Modified Glassy Carbon Electrode as a Sensor for the Voltammetric Detection of L-Tryptophan at Physiological pH. J Forensic Sci Res. 2017; 1: 001-009. https://doi.org/10.29328/journal.jfsr.1001001 
method for the determination of Trp in food products, pharmaceuticals and biological fluids is necessary and is likely to have great significance in life science research and drug analysis. Several methods that have been used for the determination of Trp in different samples include chromatography, chemiluminescence, spectrophotometry, fluorimetry, flow injection analysis and electrophoresis [12,13]. Nevertheless, these methods are complex, time-consuming, expensive and often suffer from selectivity or specificity and pretreatment or require derivatization prior to its determination [14]. Trp being an electroactive compound, electroanalytical techniques provide an alternate way to analyze Trp with certain advantages such as quick response, high sensitivity, high selectivity, and inexpensiveness, amenability to miniaturization, low power consumption and wide linear dynamic range [15]. However, the electrochemical detection of Trp faces some problems. At traditional working electrodes, Trp follows a sluggish kinetics and has very high oxidation overpotential $[16,17]$. The other electroactive biomolecules which coexist with Trp in biological matrices interfere with the determination of Trp due to their similar oxidation peak potentials. These problems are solved by modifying the electrodes with suitable materials using various modification methods [18]. Many materials have been used to modify the traditional working electrodes for the determination of Trp [19].

Most recently, we developed a facile and effective one step electropolymerization method for the preparation of PDA- $\beta$-CD on the surface of GCE [20]. Using this one pot electrosynthesis, $\beta$-CD can be effectively embedded on PDA to form PDA- $\beta$-CD. The as-prepared PDA- $\beta$-CD shows favorable electroactivity towards some amino acids (L-Cysteine, L-Tyrosine, L-Glycine, and L-Phenylalanine) oxidation.

Based on excellent electroactivity of PDA- $\beta$-CD film towards determination of some amino acids and at continuing our previously report [20], in this report the performance of PDA- $\beta$-CD-GCE was evaluated towards electrooxidation and determination of L-Trp. The aim of this communication is merely to expand application of PDA- $\beta$-CDGCE towards the kinetic and analytical investigates of L-Trp. Our objective in the present work was to develop a simple voltammetric sensor for the determination of Trp which is free from all interfering molecules. Even though there are several reports for the fabrication of a sensor for the determination of Trp, the focus happens to be on complicated procedures of modifications. Hence, a sensor with a simple method of preparation is much desired. In this study, our aim was to use a simple and convenient method of modification i.e. electropolymerization PDA- $B$-CD on a glassy carbon electrode as the underlying surface in order to fabricate a highly sensitive sensor with better lower detection limits and free from interferences from other biomolecules which coexist with L-Trp. Electrochemical investigation of L-Trp at this modified electrode reveals its electroactivity towards L-Trp. Analytical applications of the modified electrode were demonstrated by estimating the L-Trp in the standard solution.

\section{EXPERIMENTAL}

All of experimental procedure is similar to our previous report [20]. All chemicals used were of analytical grade from Merck (Darmstadt, Germany) and were used without further purification. All solutions were prepared with doubly distilled water. Electrochemical measurements were carried out in a conventional three-electrode cell (from Metrohm) powered by an electrochemical system comprising of AUTOLAB system with PGSTAT302N (Eco Chemie, Utrecht, The Netherlands). The system was run on a PC using NOVA software. The ac voltage amplitude used was $10 \mathrm{mV}$ and the equilibrium time was $5 \mathrm{~s}$. An Ag/AgCl-Sat'd $\mathrm{KCl}$ (from Metrohm) and a platinum wire were used as reference and counter electrodes, respectively. The working electrode was GCE ( $\mathrm{d}=2 \mathrm{~mm}$ ) (from Azar electrode Co., Iran) and PDA- $\beta$-CD-GCE. For DPV measurements, a pulse width of $25 \mathrm{mV}$, a pulse time of $50 \mathrm{~ms}$, and a scan rate 
of $50 \mathrm{mVs}-1$ were employed. The surface morphology of the modified electrodes was evaluated with a Vega-Tescan electron microscope (SEM, Hitachi Ltd., Tokyo, Japan).

\section{RESULTS AND DISCUSSIONS}

The cyclic voltammograms of GCE, PDA-GCE and PDA- $\beta$-CD-GCE were recorded between -1.0 and $1.0 \mathrm{~V}$ using the scan rate of $100 \mathrm{mVs}^{-1}$ in the $0.1 \mathrm{M} \mathrm{PBS}(\mathrm{pH}=7.4)$ in the presence of L-Trp. As seen in Figure. 1A-C, on the bare GCE electrode (curve a) no redox behavior was observed. On the other hand, as well as on the PDA-GCE and PDA$\beta$-CD-GCE (curves band c) one pair redox peaks was appeared at $0.14 \mathrm{~V} v \mathrm{~s}$. Ag/AgCl. The comparison of recorded CVs using PDA-GCE and PDA- $\beta$-CD-GCE in the presence of L-Trp. Figure $1 \mathrm{C}$ shows a new anodic peak at $0.657 \mathrm{~V}$ on the surface of PDA- $\beta$-CD-GCE which attribute to the anodic oxidation of L-Trp using PDA- $\beta$-CD-GCE. Therefore, PDA$\beta$-CD is a suitable mediator to shuttle electron between L-Trp and working electrode, and facilitate electrochemical regeneration following electron exchange with L-Trp.

The electrochemical behaviors of L-Trp at different scan rates were investigated on the surface of PDA- $\beta$-CD-GCE by CV. Scan rate is one of parameters significantly affecting electrooxidation of various compounds. Thus, the effect of the scan rate on L-Trp electrooxidation was investigated in the range from 2-1000 $\mathrm{mVs}^{-1}$ using CV method (Figure 2A). A linear relationship was obtained between the peak current and the scan rate in the range of $2-75 \mathrm{mVs}^{-1}$, which revealed that the oxidation of L-Trp was an adsorption-controlled step (Figure 2B). Two approaches widely used to study the reversibility of reactions and to determine whether a reaction is adsorption or diffusion controlled consists of the analyses of dependences: Ip $v s v^{1 / 2}$ and $\ln$ Ip $v s \ln v$. Figure 2C shows these plots for the oxidation peak of L-Trp in 0.1M PBS ( $\mathrm{pH}=7.4)$. For irreversible systems without kinetic complications, $\mathrm{I}_{\mathrm{p}}$ varies linearly with $v^{1 / 2}$, intercepting the origin. Although, the plot of Ip on $v^{1 / 2}$ presented in Figure $2 \mathrm{C}$ is linear $\left(\mathrm{R}^{2}=0.9982\right)$, it does not cross the origin of the axes. This is characteristic for the electrodic process preceded by electrochemical reaction and followed by a homogenous chemical reaction. In the scan rate range from 2-1000 $\mathrm{mVs}^{-1}$, peak current $\left(\mathrm{I}_{\mathrm{p}}\right)$ of L-Trp electrooxidation depends linearly on square root of the scan rate $(v)$ and is described by the equation 1 :

$$
I_{p}=0.0186 v\left(V^{1 / 2} \mathrm{~s}^{-1}\right) \cdot \mu \mathrm{A}+0.0784 \mu \mathrm{A}\left(\mathrm{R}^{2}=0.9982\right)
$$

This dependence does not cross the origin. This fact can suggest that the electrode process of L-Trp electrooxidation isn't controlled by diffusion and can be preceded by chemical reaction. On the other hand, a dependence of $\ln \mathrm{I}_{\mathrm{p}}$ on $\ln v$ is linear and described by the equation 2 :

$$
\ln I_{p}=\left\{0.771 \ln v\left(V^{-1}\right)\right\}-9.122 m A\left(R^{2}=0.9963\right)
$$

Its slope is 0.771 and indicates adsorption-control of the electrode process. A slope close to 0.5 is expected for diffusion-controlled electrode processes and close to 1.0 for adsorption-controlled processes [21-24].

Figure 2D presents a dependence of $E_{p}$ on scan rate determined from cyclic voltammograms recorded for the L-Trp electrooxidation. If electrochemical reaction is irreversible, then $\mathrm{E}_{\mathrm{p}}$ is independent on $v$. Thus, it can be concluded that heterogeneous electron transfer in L-Trp electrooxidation is irreversible because $\mathrm{E}_{\mathrm{p}}$ increases with an increase in the scan rate. In addition, the value of the overall electron transfer coefficient for the reaction can be obtained from the equation $3[25,26]$ :

$$
E p=\left(\frac{R T}{2 \beta n F}\right) \ln v+\text { constant }
$$

where $\mathrm{E}_{\mathrm{p}}$-peak potential (V), R-universal gas constant $\left(8.314 \mathrm{~J} \mathrm{~K}^{-1} \mathrm{~mol}^{-1}\right)$, F-Faraday 
constant $\left(96,487 \mathrm{C} \mathrm{mol}^{-1}\right)$, T-Kelvin temperature $(298 \mathrm{~K}), \beta n$-anodic transfer coefficient, $v$-scan rate $\left(\mathrm{V} \mathrm{s}^{-1}\right)$.

Using the dependence of anodic peak potential on the logarithm of the potential scan rate, the value of the overall electron transfer coefficient $(\beta n)$ was obtained as 0.13 for L-Trp electro-oxidation.

In order to obtain information on the rate-determining step, Tafel slope (b = RT/ $\beta n F$ ) was determined as $6.77 \mathrm{mV}$.

According to Bard and Faulkner [23], current-potential characteristic of the oxidation irreversible process is described by the equation 4 [23]:

$$
I p=0.227 \mathbf{F A C} *[\exp (\beta n f)(E p)]
$$

where $I_{p}$-peak current $(A), f=F / R T, A$-electrode area $\left(\mathrm{cm}^{2}\right)$, C-bulk concentration of L-Trp $\left(\mathrm{mol} \mathrm{cm}^{-3}\right)$, and. This equation allowed obtaining dependence:

$$
\operatorname{Ln} I p=\operatorname{Ln} a-(\beta n f) E p
$$

A dependence of $\ln \left(\mathrm{I}_{\mathrm{p}}\right) v s$. $\left(\mathrm{E}_{\mathrm{p}}\right)$ is linear and described by the equation 5:

$\ln I p=\left\{6.26\left[\left(E_{p}\right) V\right]\right\} \mathrm{mA}-12.68 \mathrm{~mA}\left(\mathrm{R}^{2}=0.9856\right)[5]$ and its slope is 2.33. Therefore, anodic transfer coefficient $(\beta n)$ of L-Trp electrooxidation, calculated from the a Eq. (3) totals $100 \mathrm{mV}$. This result is close to obtained from previous method $\left(\mathrm{E}_{\mathrm{p}} v s\right.$. $\left.\ln v\right)$. This slop indicates also the three electron transfer to be rate-limiting, assuming a charge transfer coefficient of $\beta=0.18$.

In order to develop a voltammetric method for determining of L-Trp, we selected the DPV mode, because the peaks are sharper and better defined at lower concentrations of L-Trp than those obtained by CV, with a lower background current,

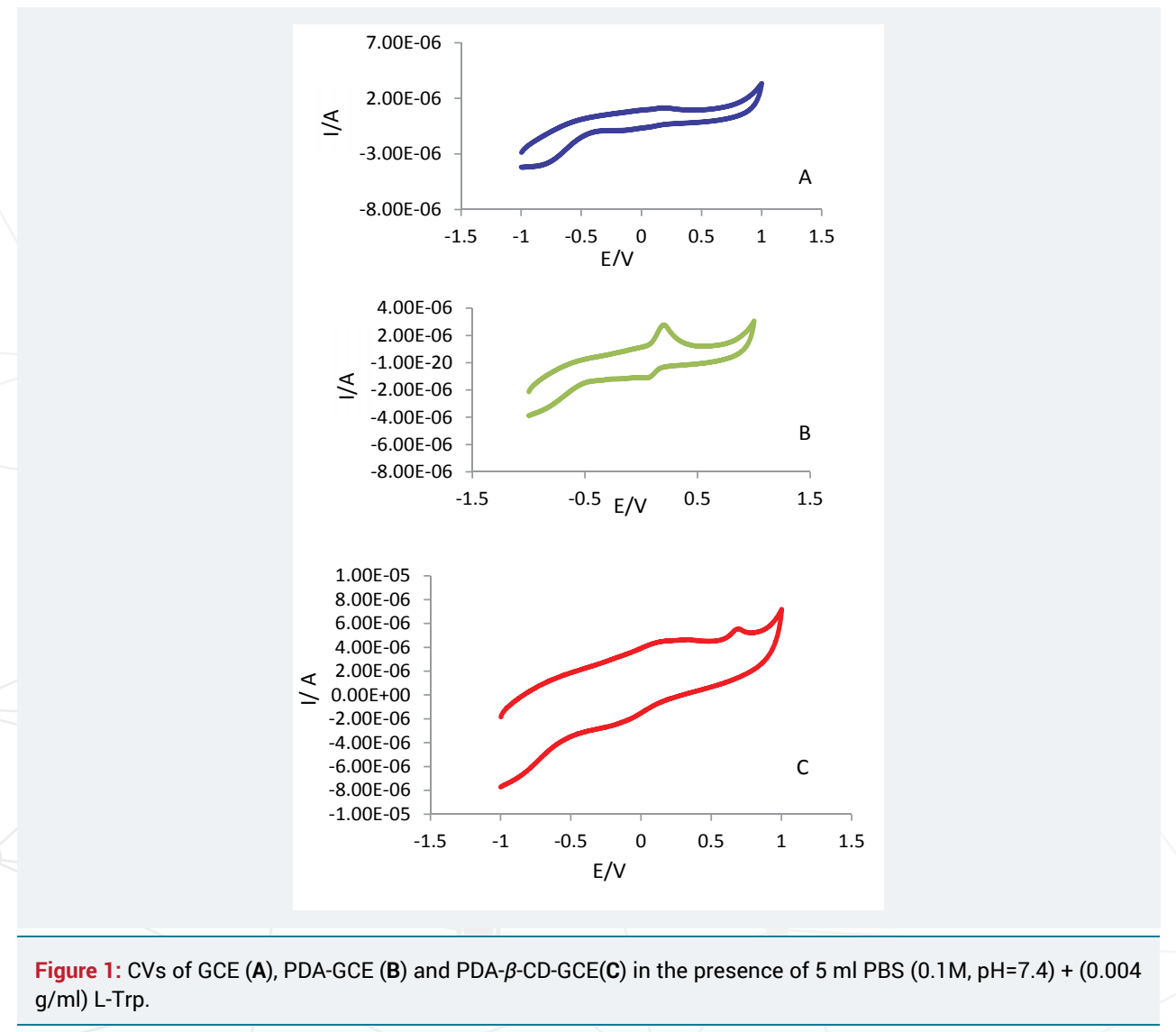


resulting in improved resolution. According to the obtained results, it was possible to apply this technique to the quantitative analysis of L-Trp. As mentioned previously, the PBS (pH 7.4) was selected as the supporting electrolyte for the quantification of L-Trp. The linear range for the determination of L-Trp in the standard samples was investigated under optimal conditions. The linear range for L-Trp was 0.08-150 $\mu \mathrm{M}$. In addition LLOQ values were $0.08 \mu \mathrm{M}$, respectively. Figure 3 illustrates the DPVs for determination of L-Trp samples.

Analytical performance of PDA- $\beta$-CD-GCE has been compared with other reported electrodes and the results are shown in Table 1 [27-38]. Binuclear manganese (II) complex modified CPE requires $60.0 \mathrm{~s}$ accumulation times prior to the determination of Trp and moreover, the energy required to oxidize Trp at this electrode was more as compared to PDA- $\beta$-CD-GCE [28]. The preparation of carbon nanofibers (CNFs) needs sophistication and apart from that none of the analytical applications of CNF-
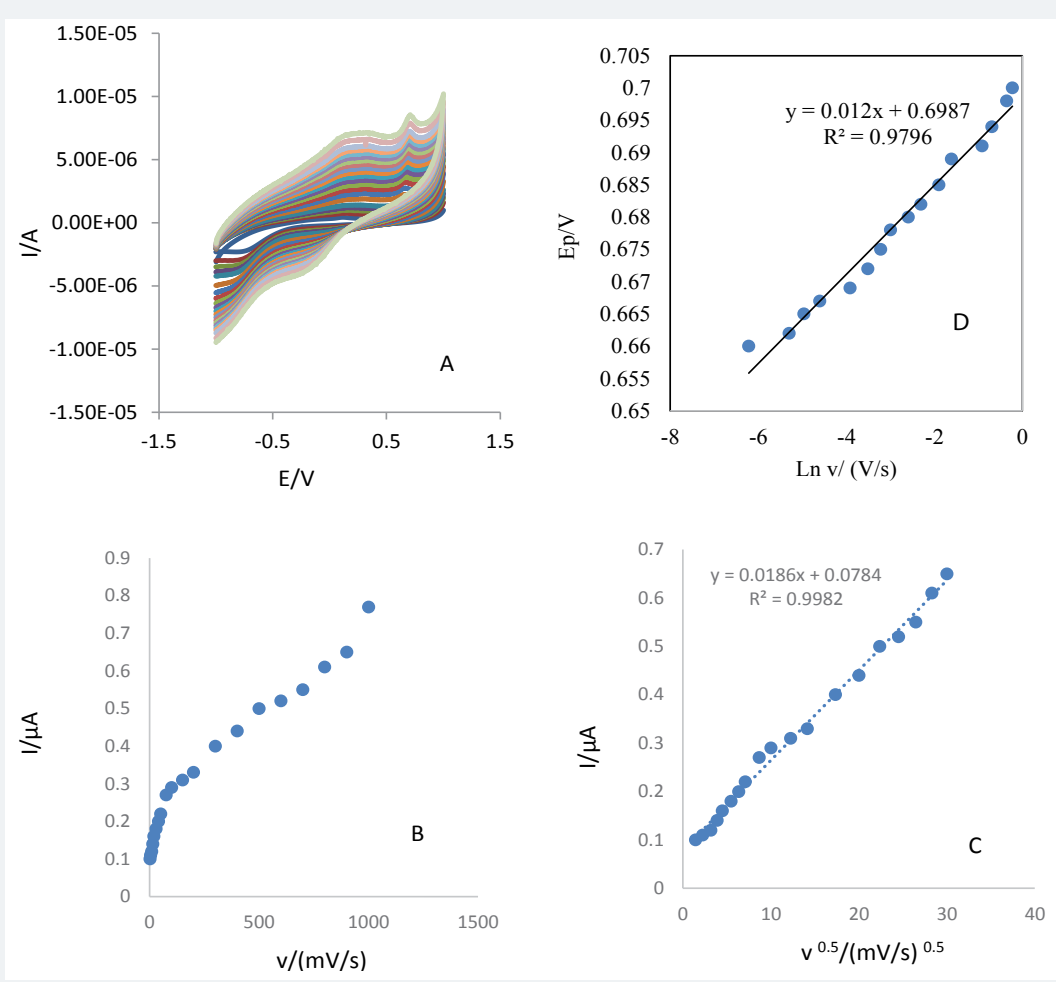

Figure 2: A) CVs of PDA- $\beta$-CD-GCE in the presence of $0.1 \mathrm{M} \mathrm{PBS}(\mathrm{pH}=7.4)$ and $0.005 \mathrm{~g} / \mathrm{ml}$ of L-Trp in different scan rates (from inner to outer): 2-1000 $\mathrm{mV} \mathrm{s}^{-1}$, respectively. B) Dependence of anodic peak current (Ip) on the scan rate. C) Dependence of anodic peak current (Ip) on the square root of potential scan rate. D) Dependence of the anodic peak potential on Ln $v$ for the oxidation of L-Trp at PDA- $\beta$-CD-GCE.

Table 1: Comparison of PDA- $\beta-C D-G C E$ with other working electrodes.

\begin{tabular}{|l|c|c|c|c|c|}
\hline Electrode. & $\mathbf{p H}$ & $\begin{array}{c}\text { Linear } \\
\text { range }(\mu \mathrm{M})\end{array}$ & $\begin{array}{c}\text { Detection limit } \\
(\mu \mathrm{M})\end{array}$ & $\begin{array}{c}\text { Technique } \\
\text { used }\end{array}$ & Refs \\
\hline CPE/binuclear manganese(II) complex & 4.1 & $0.1-1$ & 0.08 & LSV & 29 \\
\hline CNF-CPE & 7.0 & $0.1-119$ & 0.1 & Amperometry & 30 \\
\hline CILE & 2.8 & $8-1000$ & 0.48 & CV & 31 \\
\hline CPE/SiO & 2.0 & $0.1-5$ & 0.36 & LSV & 32 \\
\hline ERGO/GCE & 6.5 & $0.2-40$ & 0.1 & & 33 \\
\hline PAA/GCE & 7.4 & $1-500$ & 0.081 & DPV & 34 \\
\hline CoSal-CNTPE & 4.0 & $0.5-50$ & 0.1 & LSV & 35 \\
\hline Ag@C/GCE & 2.0 & $0.1-100$ & 0.04 & DPV & 37 \\
\hline BDD NWS & 11.0 & $0.5-50$ & 0.5 & SWV & 38 \\
\hline GNP/CILE & 7.0 & $5-900$ & 4 & DPV & This work \\
\hline PDA- $\beta$-CD-GCE & 7.4 & $0.08-150$ & 0.08 & & 36 \\
\hline
\end{tabular}


CPE have been reported [29]. Acidic medium was required for the electrocatalysis of CILE towards Trp [30]. An accumulation time of $1100.0 \mathrm{~s}$ and $180.0 \mathrm{~s}$ was required for the determination of Trp at CPE/SiO 2 [31] and ERGO/GCE [32] respectively. PAA/GCE suffers serious interference from tyrosine (Tyr) [33]. This setback was not observed at MCPE/MWCNTs. Trp oxidation at CoSal-CNTPE required a very high oxidation over potential [34]. Ag@C core-shell nanocomposites preparation was tedious and it required an electrochemical pre-treatment of glassy carbon electrode prior to the preparation of Ag@C/GCE [35]. The oxidation overpotential at expensive BDD NWs [36] was very high and it required a highly basic medium for the electrocatalytic oxidation of Trp. A two-step procedure was involved in the preparation of GNP/ CILE [37]. The PDA- $\beta$-CD-GCE has certain advantages as compared to glassy carbon (GC) electrode modified with MWCNTs; GC/MWCNT [38]. The GC/MWCNT requires an accumulation time before each measurement while PDA- $\beta$-CD-GCE has an advantage of easily preparation and accumulation time is not required before any measurement. The electrochemical oxidation of Trp was observed at $0.97 \mathrm{~V}$ by GC/ MWCNT while the same by PDA- $\beta$-CD-GCE were observed at $0.657 \mathrm{~V}$. Hence, L-Trp requires less oxidation over potential at PDA- $\beta$-CD-GCE as compared to GC/MWCNT. The detection limit of Trp at GC/MWCNT was $27 \mathrm{nM}$. The detection limit achieved at PDA- $\beta$-CD-GCE was comparable with that achieved at GC/MWCNT apart from having an additional advantage of achieving it at physiological $\mathrm{pH}$. Comparing with most of the aforementioned modified electrodes, a much better current sensitivity and wide linear dynamic range is achieved at PDA- $\beta$-CD-GCE without involving any complicated and time-consuming methods of preparation. The oxidation over potential of Trp was considerably reduced at PDA- $\beta$-CD-GCE under physiological conditions and so we can easily extend its applications to biological fields. These facts make PDA- $\beta$-CD-GCE a potential electrochemical sensor for the determination of Trp for various applications.

\section{CONCLUSIONS}

In conclusion, we have expanded application of poly-dopamine-beta-cyclodextrin modified glassy carbon electrode (published in Materials Science and Engineering C 69 (2016) 343-357) towards detection and determination of L-Try. In this work, we have described a simple and rapid voltammetric method for the quantification of L-Trp under physiological $\mathrm{pH}$ by modifying the GCE with PDA- $\beta$-CD. Decrease in oxidation overpotential and enhancement in current proved the electrocatalytic activity of

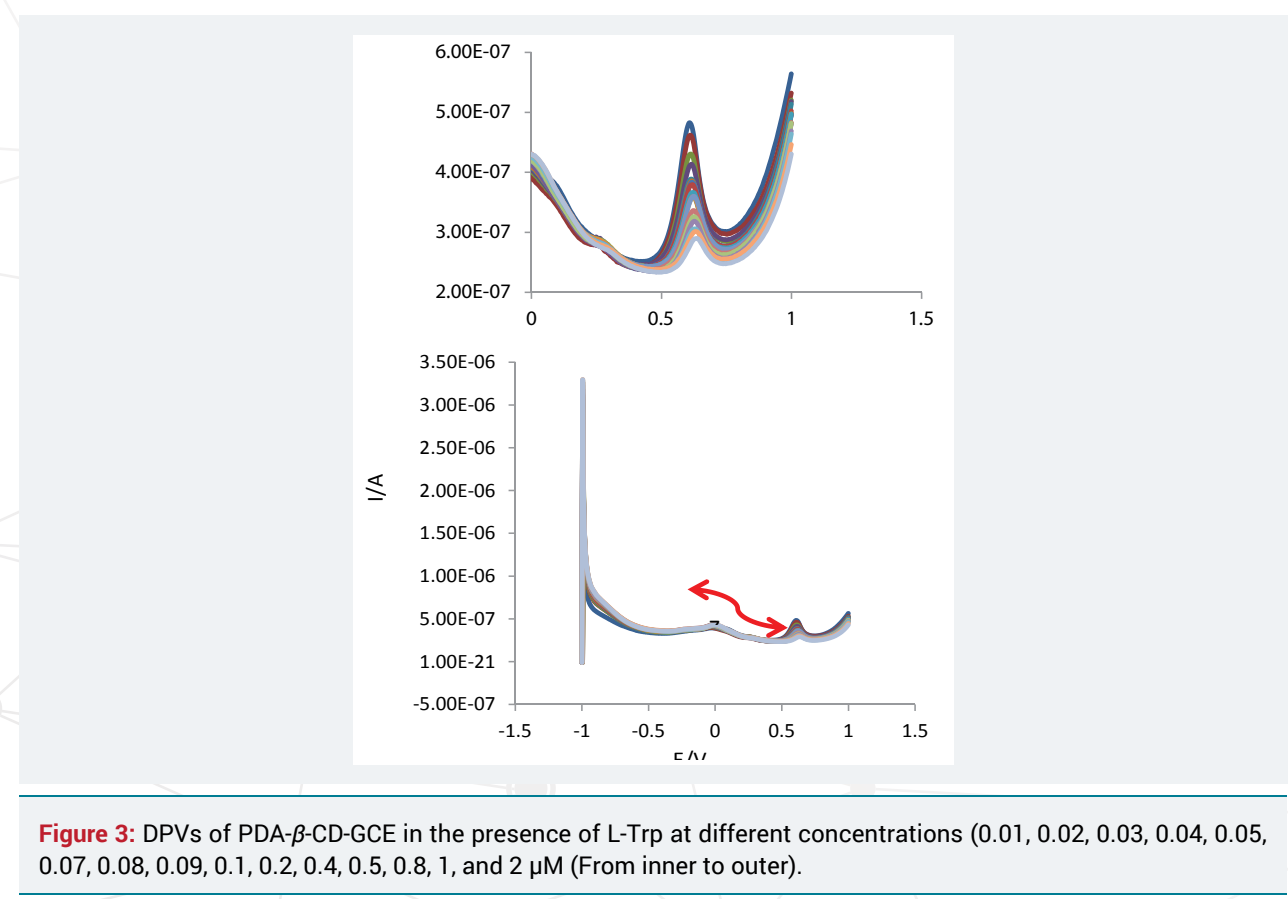



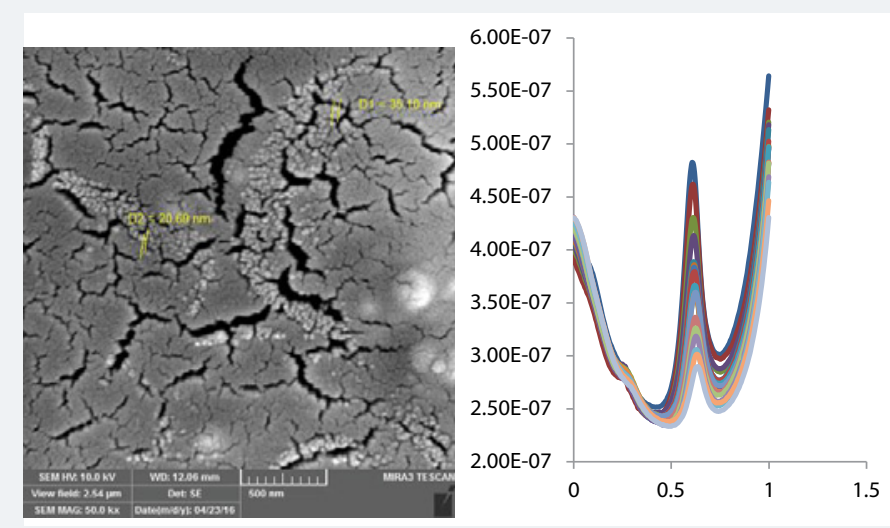

Graph:

PDA- $\beta$-CD-GCE as a sensor. Importantly, by this simple method of fabrication a much lower detection limit was achieved without involving any pre-treatment or activation steps. The analytical applicability of the modified electrode has been evaluated by successfully employing it for the determination of L-Trp in the standard solution. The low cost, simple method of preparation, high efficiency and quick response time makes employing this electrode convenient for routine analysis of L-Trp in different fluids.

\section{ACKNOWLEDGEMENTS}

We gratefully acknowledge the partial financial support by Drug Applied Research Center Research Center, Tabriz University of Medical Sciences.

\section{REFERENCES}

1. Wang $\mathrm{H}$, Cui $\mathrm{H}$, Zhang $\mathrm{A}$, Liu R. Adsorptive stripping voltammetric determination of tryptophan at an electrochemically pre-treated carbon-paste electrode with solid paraffin as a binder. Anal Commun. 1996; 33: 275-277. Ref.: https://goo.gl/PpUEw3

2. Ensafi AA, Maleh HK, Mallakpour S. Simultaneous Determination of Ascorbic Acid, Acetaminophen, and Tryptophan by Square Wave Voltammetry Using N (3,4 Dihydroxyphenethyl) 3,5 Dinitrobenzamide Modified Carbon Nanotubes Paste Electrode. Electroanalysis. 2012; 24: 666-675. Ref.: https://goo.gl/M9yyYv

3. Kia M, Islamnezhad A, Shariati S, Biparva P. Preparation of voltammetric biosensor for tryptophan using multi-walled carbon nanotubes. Korean J Chem Eng. 2011; 28: 2064-2068. Ref.: https://goo.gl/rNfJTy

4. Li C, Ya Y, Zhan G. Electrochemical investigation of tryptophan at gold nanoparticles modified electrode in the presence of sodium dodecylbenzene sulfonate. Colloids Surf B. 2010; 76: 340-345. Ref.: https://goo.gl/ZD48qj

5. Raoof JB, Ojani R, Baghayeri M. Simultaneous electrochemical determination of glutathione and tryptophan on a nano-TiO2/ferrocene carboxylic acid modified carbon paste electrode. Sens. Actuat B. 2009; 143: 261-269. Ref.: https://goo.gl/Pfz8Lr

6. Li W, Li C, Kuang Y, Deng P, Zhang S, et al. A carbon paste electrode modified with a cobalt(II) coordination polymer for the direct voltammetric determination of tryptophan. Microchim Acta. 2012; 176: 455-461. Ref.: https://goo.gl/hSSSAL

7. Mirrahimi F, Taher MA, Beitollahi H, Hosseinzadeh R. Electrocatalytic and selective determination of d-penicillamine in the presence of tryptophan using a benzoylferrocene-modified carbon nanotube paste electrode. Appl Organomet Chem. 2012; 26: 194-198. Ref.: https://goo.gl/tQz0jr

8. Goyal RN, Bishnoi S, Chasta H, Aziz MA, Oyama M. Effect of surface modification of indium tin oxide by nanoparticles on the electrochemical determination of tryptophan. Talanta. 2011; 85: 2626-2631. Ref.: https://goo.gl/rdkoaM

9. Prabhu P, Babu RS, Narayanan SS. Electrocatalytic oxidation of L-tryptophan using copper hexacyanoferrate film modified gold nanoparticle graphite-wax electrode. Colloids Surf B. 2011; 87: 103-108. Ref.: https://goo.gl/AeQbQ2

10. Fan Y, Liu JH, Lu HT, Zhang Q. Electrochemistry and voltammetric determination of L-tryptophan 
and L-tyrosine using a glassy carbon electrode modified with a Nafion/TiO2-graphene composite film. Microchim Acta. 2011; 173: 241-247. Ref.: https://goo.gl/GI8pYy

11. Shahrokhian S, Bayat M. Pyrolytic graphite electrode modified with a thin film of a graphite/ diamond nano-mixture for highly sensitive voltammetric determination of tryptophan and 5-hydroxytryptophan. Microchim Acta. 2011; 174: 361-366. Ref.: https://goo.gl/COLt9P

12. Akhgar MR, Salari M, Zamani H. Simultaneous determination of levodopa, NADH, and tryptophan using carbon paste electrode modified with carbon nanotubes and ferrocenedicarboxylic acid. J Solid State Electrochem. 2011; 15: 845-853. Ref.: https://goo.gl/iCliL7

13. Deo RP, Lawrence NS, Wang J. Electrochemical detection of amino acids at carbon nanotube and nickelcarbon nanotube modified electrodes. Analyst. 2004; 129: 1076-1081. Ref.: https://goo.gl/a7k201

14. Dong S, Zhang S, Chi L, He P, Wang Q, et al. Electrochemical behaviors of amino acids at multiwall carbon nanotubes and Cu2O modified carbon paste electrode. Anal Biochem. 2008; 381: 199-204. Ref.: https://goo.gl/MjGRGA

15. Liu X, Luo L, Ding Y, Kang Z, Ye D. Simultaneous determination of L-cysteine and L-tyrosine using Aunanoparticles/poly-eriochrome black T film modified glassy carbon electrode. Bioelectrochemistry. 2012; 86: 38-45. Ref.: https://goo.gl/4rYGyG

16. MacDonald SM, Roscoe SG. Electrochemical oxidation reactions of tyrosine, tryptophan and related dipeptides. Electrochim Acta. 1997; 42: 1189-1200. Ref.: https://goo.gl/ecL64l

17. Ye D, Luo L, Ding Y, Liu B, Liu X. Fabrication of Co304 nanoparticles-decorated graphene composite for determination of L-tryptophan. Analyst. 2012; 137: 2840-2845. Ref.: https://goo.gl/Qa4a3L

18. Nan CG, Feng ZZ, Li WX, Ping DJ, Qin CH. Electrochemical behavior of tryptophan and its derivatives at a glassy carbon electrode modified with hemin. Anal Chim Acta. 2002; 452: 245 254. Ref.: https://goo.gl/03JFdu

19. Guo Y, Guo S, Fang Y, Dong S. Gold nanoparticle/carbon nanotube hybrids as an enhanced material for sensitive amperometric determination of tryptophan. Electrochim Acta. 2010; 55: 3927-3931. Ref.: https://goo.gl/6AITnB

20. Hasanzadeh M, Sadeghi S, Bageri L, Mokhtarzadeh A, Karimzadeh A, et al. Poly-dopamine-betacyclodextrin: A novel nanobiopolymer towards sensing of some amino acids at physiological $\mathrm{pH}$. Materials Science and Engineering: C. 2016; 69: 343-357. Ref.: https://goo.gl/ZQLfSR

21. Xu J, Shang F, Luong JH, Razeeb KM, Glennon JD. Direct electrochemistry of horseradish peroxidase immobilized on a monolayer modified nanowire array electrode. Biosens Bioelectron. 2010; 25: 1313-1318. Ref.: https://goo.gl/mC7XN0

22. Kissinger $P$, Heineman WR. Laboratory Techniques in Electroanalytical Chemistry, 2nd edition. $C R C$ Press. 1996; 224. Ref.: https://goo.gl/R8aLMx

23. Bard AJ, Faulkner LR. Electrochemical methods: fundamentals and applications, 2nd edition. John Wiley \& Sons. 2001; 236, 503 and 709. Ref.: https://goo.gl//HWNCG

24. Brett $\mathrm{CM}$, Brett $\mathrm{AO}$. Electrochemistry: principles, methods and applications. Oxford University Press. 1993; 427. Ref.: https://goo.gl/KJGhjg

25. Pariente F, Lorenzo E, Tobalina F, Abruna H D. Aldehyde Biosensor Based on the Determination of NADH Enzymically Generated by Aldehyde Dehydrogenase. Anal. Chem. 1995; 67: 3936-3944. Ref.: https://goo.gl/GmreuX

26. Harrison JA, Khan ZA. The oxidation of hydrazine on platinum in acid solution. J Electroanal Chem Interfacial Electrochem. 1970; 28: 131-138. Ref.: https://goo.gl/MIMhlr

27. Liu X, Luo L, Ding Y, Ye D. Poly-glutamic acid modified carbon nanotube-doped carbon paste electrode for sensitive detection of L-tryptophan. Bioelectrochemistry. 2011; 82: 38-45. Ref.: https://goo.gl/zTPOK1

28. Xu J, Yuan Y, Li W, Deng P, Deng J. Carbon paste electrode modified with a binuclear manganese complex as a sensitive voltammetric sensor for tryptophan. Microchim Acta. 2011; 174: 239-245. Ref.: https://goo.gl/RztqNx

29. Tang $X$, Liu Y, Hou H, You T. Electrochemical determination of L-Tryptophan, L-Tyrosine and L-Cysteine using electrospun carbon nanofibers modified electrode. Talanta. 2010; 80: 2182-2186. Ref.: https://goo.gl/U1IRjw

30. Jiang Q, Sun W, Jiao K. Electrochemical behavior and determination of L-tryptophan on carbon ionic liquid electrode. J Anal Chem. 2010; 65: 648-651. Ref.: https://goo.gl/F95aWJ 
31. Xu M, Ma M, Ma Y. Electrochemical determination of tryptophan based on silicon dioxide nanopartilces modified carbon paste electrode. Russ J Electrochem. 2012; 48: 489-494. Ref.: https://goo.gl/nRtCK5

32. Güney S, Yıldız G. Determination of tryptophan using electrode modified with poly(9aminoacridine) functionalized multi-walled carbon nanotubes. Electrochim Acta. 2011; 57: 290-296. Ref.: https://goo.gl/UL4S2P

33. Shahrokhian S, Fotouhi L. Carbon paste electrode incorporating multi-walled carbon nanotube/ cobalt salophen for sensitive voltammetric determination of tryptophan. Sens Actuat B. 2007; 123 : 942-949. Ref.: https://goo.gl/kns7s3

34. Mao S, Li W, Long Y, Tu Y, Deng A. Sensitive electrochemical sensor of tryptophan based on Ag@C core-shell nanocomposite modified glassy carbon electrode. Anal Chim Acta. 2012; 738: 35-40. Ref.: https://goo.gl/93j5YD

35. Deng KQ, Zhou JH, Li XF. Direct electrochemical reduction of graphene oxide and its application to determination of L-tryptophan and L-tyrosine. Colloids Surf B. 2013; 101: 183-188. Ref.: https://goo.gl/t8eDEe

36. Szunerits S, Coffinier Y, Galopin E, Brenner J, Boukherroub R. Electrochem Commun. 2010; 12: 438441. Ref.: https://goo.gl/GNdG80

37. Safavi A, Momeni S. Electrocatalytic Oxidation of Tryptophan at Gold Nanoparticle-Modified Carbon Ionic Liquid Electrode. Electroanalysis. 2010; 22: 2848-2855. Ref.: https://goo.gl/FsEzql 